\title{
POTENCIAL PRODUTIVO DE CULTIVARES DE MORANGUEIRO ${ }^{1}$
}

\author{
AMANDA GONÇALVES GUIMARÃES², VALTER CARVALHO DE ANDRADE JÚNIOR², \\ AHMED YOUSSEF ABDELNABI MOHAMED ELSAYED ${ }^{4}$, \\ JOSÉ SEBASTIÃO CUNHA FERNANDES ${ }^{3}$, MARCOS AURÉLIO MIRANDA FERREIRA ${ }^{5}$
}

RESUMO- O objetivo foi avaliar o potencial produtivo de cultivares de morangueiro em região representativa do Alto Jequitinhonha. O experimento foi conduzido na fazenda Mape Frutas Ltda., localizada no município de Datas-MG, em delineamento em blocos ao acaso, com oito cultivares de morangueiro em quatro repetições, para verificar a produção de mudas e de frutos. A contagem da produção de estolões e de mudas foi realizada aos 180 dias após o plantio. A avaliação das variáveis relacionadas à produção de frutos foi feita duas vezes por semana, no período de maio a outubro de 2012. Das cultivares de dias curtos (Festival, Campinas, Toyonoka, Dover, Oso Grande e Camarosa) e dias neutros (Diamante e Aromas), apenas Toyonoka foi a que apresentou menor desempenho para as variáveis. A significativa superioridade das cultivares Camarosa e Festival, para praticamente todas as variáveis avaliadas, permite recomendá-las para regiões com características edafoclimáticas semelhantes às da região onde o experimento foi conduzido. Dentre as cultivares avaliadas, as mais precoces tenderam a apresentar maior desempenho para variáveis relacionadas à produção de frutos. Termos para Indexação: Fragaria $x$ ananassa Duch, colheita, rendimento.

\section{PRODUCTIVE POTENTIAL OF STRAWBERRY CULTIVARS}

\begin{abstract}
This study was conducted in order to evaluate the productive potential of strawberry cultivars in a representative region of Alto Jequitinhonha - Brazil. The experiment was conducted at farm Mape Frutas Ltda, located in the municipality of dates, MG, in randomized block design with eight strawberry cultivars in four replications to verify the production of seedlings and fruit. Counting of production of stolons and seedlings was performed at 180 days after planting. The assessment of variables related to fruit production was done twice a week from May to October 2012. Cultivars of short days (Festival, Campinas, Toyonoka, Dover, Oso Grande and Camarosa) and day neutral (Diamante and Aromas), only Toyonoka showed the lowest performance for the variables. The significant superiority of the cultivars Camarosa and Festival for virtually all variables allows recommends it for regions with similar climatic edaphic characteristics of the region where the experiment was conducted. Among the cultivars, the earlier tended to have higher performance for variables related to fruit production. Index terms: Fragaria x ananassa Duch, crop, yield.
\end{abstract}

\footnotetext{
(Trabalho 400-13). Recebido em: 15-10-2013. Aceito para publicação em: 12-08-2014.

${ }^{2}$ Doutoranda da Universidade Estadual Norte Fluminense Darcy Ribeiro (UENF). Centro de Ciências e Tecnologias Agropecuárias. Av. Alberto Lamego, 2000 - Parque Califórnia - Campos dos Goytacazes/ RJ - 28013-602. Email: amandagguimaraes@yahoo.com.br ${ }^{3}$ Professor Doutor da Universidade Federal dos Vales do Jequitinhonha e Mucuri (UFVJM). Departamento de Agronomia. Rodovia MGT367-Km 583, № 5000. Bairro Alto da Jacuba Diamantina/MG CEP 39100-000 Email: valterjr@ufvjm.edu.br; cunha.fernandes@ yahoo.com.br

${ }_{4}^{4}$ Pós Doutorando na UFVJM. Departamento de Agronomia. Rodovia MGT 367 -Km 583, № 5000. Bairro Alto da Jacuba Diamantina/ MG CEP 39100-000 Email: ahmedtohy@yahoo.com

${ }^{5}$ Graduando de Agronomia da UFVJM. Departamento de Agronomia. Rodovia MGT 367 -Km 583, № 5000. Bairro Alto da Jacuba Diamantina/MG CEP 39100-000 Email: marcosmamf23@yahoo.com.br
} 


\section{INTRODUÇ̃̃O}

O morangueiro (Fragaria $x$ ananassa Duch.) é produzido e apreciado nas mais variadas regiões do mundo, sendo a cultura destacada pela alta rentabilidade por área e demanda intensa de mão de obra (OLIVEIRA et al., 2008). Sua comercialização pode ser in natura, processada ou congelada (OLIVEIRA et al., 2010a).

O Brasil, apesar de não se encontrar entre os principais produtores mundiais, apresenta distribuição em regiões de climas predominantemente temperado e subtropical (OLIVEIRA; SCIVITTARO, 2009). Os estados de maior produção brasileira são Minas Gerais (40.245 t), Rio Grande do Sul (9.819 t), Paraná (6.265 t) e São Paulo (5.030 t) (EMBRAPA, 2011). No município de Datas, região do Alto Vale do Jequitinhonha, em Minas Gerais, o cultivo do morangueiro teve início no ano de 2005 e vem ganhando espaço, devido às condições climáticas e ambientais favoráveis (GUIMARAES et al., 2013).

Os fatores ambientais, principalmente temperatura, fotoperíodo e suas interações, exercem importante papel no crescimento, desenvolvimento e produção do morangueiro (SILVA et al., 2007). $\mathrm{Na}$ fase vegetativa, o desenvolvimento dos estolhos necessita de temperaturas altas e fotoperíodos longos, enquanto na fase reprodutiva, para a produção de flores, as temperaturas devem ser amenas; e os fotoperíodos, curtos (RIOS, 2007).

O plantio do morangueiro é feito através de mudas oriundas por propagação vegetativa dos estolhos emitidos pela planta. A obtenção destas mudas é realizada por viveiristas registrados e sujeitos a fiscalização. No entanto, muitos produtores produzem suas próprias mudas.

Além das diferenças em relação à produção de mudas, têm-se observado variações de produtividade entre as cultivares de morangueiro, em função de fatores fisiológicos, genéticos e ambientais (CAMARGO et al., 2010).

A avaliação de cultivares a serem plantadas em uma nova região é fundamental, pois possibilita a seleção de plantas com melhores características produtivas e qualitativas, implicando maiores benefícios econômicos (DUARTE FILHO et al., 2007). Mesmo para regiões com tradição de cultivo, a avaliação de novas cultivares é uma informação imprescindível, para que os produtores possam tomar suas decisões, em relação à substituição de variedades antigas.

O presente trabalho teve por objetivo avaliar o potencial produtivo de cultivares de morangueiro nas condições do Alto Vale do Jequitinhonha.

\section{MATERIAL E MÉTODOS}

Os trabalhos foram conduzidos na Fazenda da empresa Mape Frutas Ltda., localizada no município de Datas-MG, na região do Alto Vale Jequitinhonha, situada à latitude $-18^{\circ} 26^{\prime}$, longitude - $43^{\circ} 39^{\prime} \mathrm{e}$ altitude de $1.244 \mathrm{~m}$, em clima tropical úmido Aw, classificação de Köppen, com uma estação seca no inverno e estações chuvosas no verão, e o solo foi classificado como Neossolo quartzarênico.

A obtenção de mudas foi realizada entre os meses de setembro de 2011 e fevereiro de 2012, e o experimento para a avaliação da produção dos frutos foi instalado em março de 2012, e conduzido até outubro de 2012. Na Tabela 1, são apresentadas as médias de temperaturas máxima e mínima ocorridas durante o período de obtenção das mudas e produção de morangos.

Foram utilizadas oito matrizes de morangueiro, sendo seis de dias curtos (Festival, Campinas, Toyonoka, Dover, Oso Grande e Camarosa) e duas de dias neutros (Diamante e Aromas), provenientes da empresa Multiplanta Biotecnologia Vegetal Ltda., localizada no município de Andradas-MG.

O plantio das matrizes foi realizado no dia $1^{\circ}$ de setembro de 2011, sob cultivo protegido, em túnel baixo, coberto com plástico com 75 micras de espessura, $3 \mathrm{~m}$ de largura, $60 \mathrm{~m}$ de comprimento e 2 $\mathrm{m}$ de altura da superfície do canteiro. $\mathrm{O}$ espaçamento utilizado foi de $1 \mathrm{~m}$ entre plantas e 2,5 m entre as linhas, e o canteiro continha duas linhas, com área útil de $50 \mathrm{~m}^{2}$.

Foi feita a calagem e a adubação, considerando-se a análise do solo para $\mathrm{pH}$ e elementos convencionais, seguindo-se as recomendações para a cultura.

A irrigação foi realizada por microaspersão, programada por uma hora no período da manhã e da tarde. O controle químico de doenças e pragas foi realizado, de acordo com a avaliação periódica, durante o desenvolvimento das mudas.

Foram contados o número de estolões por planta, o número de mudas por matriz e o número de mudas por hectare, aos 180 dias após o plantio das matrizes, sendo feita uma análise descritiva dos dados.

Para a avaliação da produção dos frutos, foi utilizado o delineamento experimental em blocos casualizados, com oito tratamentos (cultivares) e quatro repetições. As mudas escolhidas para o plantio foram de acordo com os respectivos diâmetros da coroa (entre 5,10 e $8 \mathrm{~mm}$ ) e plantadas no dia $1^{\circ}$ de março de 2012, em um canteiro com $20 \mathrm{~cm}$ de altura, $64 \mathrm{~m}$ de comprimento e $1 \mathrm{~m}$ de largura. As 
parcelas experimentais foram compostas por dezoito plantas espaçadas de 0,30 x 0,30 m, em três linhas de plantio, com área útil de $2 \mathrm{~m}^{2}$, totalizando 576 mudas plantadas em um canteiro.

A calagem e a adubação também foram feitas considerando-se a análise do solo para $\mathrm{pH}$ e elementos convencionais, seguindo-se as recomendações para a cultura nesta fase.

A irrigação por aspersão foi utilizada até o pegamento das mudas e, após esse período, as plantas foram irrigadas por gotejamento. Após o pegamento das mudas, foi fixada sobre os canteiros uma cobertura com plástico (mulching) de trinta micras, de cor preta e branca, ficando a cor branca na parte superior do canteiro. Quinze dias após, foi colocado um túnel baixo coberto com plástico transparente de 75 micras de espessura, com altura de $0,80 \mathrm{~m}$ da superfície do canteiro.

A colheita dos frutos foi iniciada aos 65 dias após o plantio das mudas, quando estavam entre os estágios 50 a 75\% maduros. A avaliação durou seis meses, no período de maio a outubro de 2012, sendo a colheita realizada com uma frequência de duas vezes por semana.

Os frutos foram levados para o Laboratório de Tecnologia Biomassa do Cerrado, da Universidade Federal dos Vales do Jequitinhonha e Mucuri (UFVJM), no Câmpus JK, em Diamantina-MG, onde foram contados e pesados os frutos para o comércio in natura (descartando aqueles com massa inferior a 10 gramas).

As características avaliadas foram: a) precocidade, correspondente ao período em dias do plantio até a primeira colheita de frutos; b) produção por planta; c) produção comercial por planta; d) massa média de fruto por planta; e) massa média comercial por planta; f) número de frutos totais e comerciais por planta; g) produtividade total; h) produtividade comercial. As características dos itens (b) a (e) foram expressas em g planta ${ }^{-1}$,e as referentes aos dois últimos itens, em $\mathrm{kg} \mathrm{ha}^{-1}$.

As médias dos tratamentos cujos efeitos foram significativos pelo teste $\mathrm{F}$, a $5 \%$ de significância, foram comparadas, utilizando-se do teste Scott-Knott e do programa computacional Genes (CRUZ, 2013).

\section{RESULTADOS E DISCUSSÃO}

A análise descritiva dos dados de número de estolões por planta, de mudas por matriz e por hectare, avaliada aos 180 dias após o plantio das matrizes, encontra-se na Tabela 2.

A variação do número de estolões por matriz foi considerável entre as cultivares, sendo Aromas e Diamante as que apresentaram menores médias (Tabela 2). E as cultivares de dias neutros possuem menor sensibilidade a esses estímulos ao fotoperíodo e à temperatura que exercem sobre a emissão de estolões (STRASSBURGER et al., 2010). É possível então que a menor produção de estolões destas duas cultivares esteja ligada ao fato de serem as únicas do grupo que são de dias neutros.

O número de mudas por matriz, com implicação direta na produção de mudas por ha, também variou muito entre as cultivares (Tabela 2). Embora as duas cultivares que produziram menos estolões fossem também as que produziram menos mudas, esta tendência não se repetiu da mesma forma, considerando-se todas as cultivares, haja vista a estimativa do coeficiente de correlação ( $\mathrm{r}=$ 0,$58 ; \mathrm{P}=12,8 \%$ ) entre estas duas variáveis.

Estimativas de produção de mudas variam muito em morango. Nos trabalhos de Tessarioli Neto et al. (2003), realizados na região de Piracicaba-SP, os autores observaram diferenças na produção de mudas de morangueiro como nas cultivares Dover e Campinas, e em Toyonoka com: 338,25; 301,37 e 150,25 mudas $/ \mathrm{m}^{2}$.

O fato de não se ter repetições para os dados desta tabela impede que se faça inferências mais precisas, mas o confronto destas informações leva à conjectura de que a contribuição do ambiente na expressão desta variável não pode ser negligenciada. Além do potencial genotípico da matriz, questões como adaptação ao local e o próprio manejo da cultura podem interferir tanto na produção de estolões como no crescimento posterior da planta- matriz, as quais são fundamentais para seu desempenho (OLIVEIRA et al., 2010b).

Com efeito, comparando-se a cultivar Dover com a Diamante (Tabela 2), observa-se que a primeira produziu $212 \%$ mais mudas que a segunda. É pouco provável que esta diferença seja consequência apenas de seus potenciais genotípicos.

Em relação à avaliação das cultivares, foram observadas diferenças significativas entre estas para todas as características agronômicas avaliadas (Tabela 3). O início da colheita dos frutos (PRC) variou de 65,00 a 89,25 dias, sendo que, as Dover, Festival e Toyonoka, diferiram das demais, e que as cultivares Aromas e Diamante foram as que foram colhidas primeiro (Tabela 3). Tal resultado não surpreende, uma vez que cultivares de dias neutros possuem a habilidade de emitir flores independentemente do fotoperíodo e da temperatura (STRASSBURGER et al., 2010).

Estimativas de precocidade para algumas das cultivares testadas foram reportadas por Calvete et al. 
(2008), para o município de Passo Fundo-RS, onde as cultivares Dover, Camarosa, Oso Grande e Campinas levaram 61; 67; 61 e 78 dias, respectivamente, para florescer. Considerando-se que, além do genótipo da cultivar, fatores ambientais e qualidade da muda também têm efeitos sobre tal característica (ROSA et al., 2013), a variação observada para as estimativas entre as mesmas cultivares, no presente trabalho e nos reportados, também não surpreende.

A produção total por planta (PRT) foi representada também em $\mathrm{t} \mathrm{ha}^{-1}$ (Tabela 3) para facilitar a compreensão e permitir o confronto com dados reportados apenas nesta segunda unidade, apresentando diferenças significativas nesta variável. Considerando-se o patamar de alta produção de 700 g por planta utilizado como referencial de produtividade pelo AGRIANUAL (2008), apenas a cultivar Camarosa (526,45 g planta-1) é a que mais se aproxima deste patamar (Tabela 3). Por outro lado, observa-se que a cultivar Camarosa foi três vezes mais produtiva que Toyonoka, com uma diferença de $350 \mathrm{~g} \mathrm{planta}^{-1}$. As diferenças entre as cultivares, mesmo para o grupo dentro do qual não foram significativas, não foram desprezíveis, chegando a $160 \mathrm{~g} \mathrm{planta}^{-1}$ entre Camarosa e Diamante (Tabela 3).

A produção de frutos por planta obtida no município de Passo Fundo-RS, para as cultivares Camarosa, Oso Grande, Dover e Campinas, foram 607; 536; 549 e 232, respectivamente (CALVETE et al., 2008). Para as cultivares Aromas e Diamante, em Pelotas-RS, foram 536 e 431, respectivamente (OLIVEIRA; SCITTARO, 2008), com médias da 481 e 483 para o primeiro e o segundo grupos, respectivamente. No presente trabalho (Tabela 3), as médias para estes mesmos grupos (432 e 384, respectivamente) foram $10 \%$ e $20 \%$ inferiores às reportadas. Estas variações de produção de cultivares de morango nestes locais podem estar relacionadas a fatores fisiológicos e genéticos que são alterados pelas condições ambientais (CAMARGO et al., 2010).

Já as produtividades médias em $\mathrm{t} \mathrm{ha}{ }^{-1}$, encontradas para as cultivares Aromas, Campinas, Dover, Oso Grande e Toyonoka, no município de Guarapuava-PR, foram 12,09; 25,51; 34,06; 12,79 e 19,81, respectivamente (CAMARGO et al., 2010). No município de Ponta Grossa-PR, Otto et al. (2009) reportaram, também em t ha- ${ }^{-1}$, Diamante 31,7 e Aromas 28,4. As médias para os dois grupos referidos foram 20,85 e 30,05 , respectivamente. As médias para estes mesmos grupos, no presente trabalho (Tabela 3), foram 39,41 e 42,20, respectivamente, mostrando uma superioridade de $89 \%$ e $40 \%$, respectivamente.
O que chama mais a atenção é a divergência entre a produtividade obtida em Guarapuava e as obtidas para as mesmas cultivares no presente trabalho, talvez pelo fato de os autores terem feito a conversão para um estande diferente do utilizado no presente trabalho. As divergências para as demais estimativas estão dentro do esperado, considerandose que as condições climáticas e edáficas, incluindo-se as condições de cultivo e condução dos experimentos, foram diferentes.

Em relação à produção comercial (PCP), observa-se que determinadas cultivares não se mantiveram no mesmo nível da produção total. Cultivares em que não foram observadas diferenças significativas entre si para a produção total, apresentaram para a produção comercial (Tabela 3). Algumas cultivares, como a Dover, cuja produção total decresceu $24 \%$ em relação à mais produtiva, tiveram um decréscimo de $50 \%$ em relação à mais produtiva para a produção comercial, sendo que a mais produtiva nos dois casos foi a Camarosa (Tabela 3). Este aspecto é importante, uma vez que a produção comercial diz respeito aos frutos que efetivamente vão para o mercado.

Observações semelhantes podem ser feitas em relação ao número total de frutos por planta (NFTP) e número de frutos comerciais por planta (NFCP) (Tabela 3), o que não é de surpreender, já que cultivares que produzem mais, têm mais frutos e/ou frutos maiores. As estimativas do número total de frutos obtidas por Oliveira et al. (2008) para as cultivares Aromas e Camarosa, no município de Pelotas-RS, durante cinco meses de colheita, foram 55,2 e 55,0, respectivamente, superiores às estimativas obtidas no presente trabalho em $23 \%$ e $20 \%$, respectivamente. Já para a Dover, foram observados 78 frutos por planta no município de Passo Fundo-RS (CALVETE et al., 2008), número este $78 \%$ superior ao observado no presente trabalho (Tabela 3).

Considerando-se as variáveis PTP e NFTP, as estimativas reportadas pelos trabalhos consultados foram sempre superiores às do presente trabalho. Já que as cultivares comparadas foram as mesmas, pode-se inferir que os efeitos responsáveis por esta superioridade foram decorrentes do ambiente e/ou das interações genótipo por ambiente.

As cultivares com maior e menor massa média por fruto (MMF) foram, respectivamente, Camarosa e Dover; constatação esta que tende a se repetir para a massa média comercial por fruto (MMC) (Tabela 3). Por outro lado, observa-se que a maior diferença entre MMC e MMF ocorre para a Dover. Considerando-se que o critério que tem mais peso para se selecionar 
frutos comerciais é o tamanho destes (DUARTE FILHO et al., 2003), constata-se que a diferença MMC - MMF pode auxiliar no processo de seleção de uma cultivar. A cultivar Camarosa é a que mais se destaca, tanto para produção total como comercial. Já a Dover, apesar de não se diferir estatisticamente da Camarosa para a produção total, é significativamente inferior a esta para a produção comercial. Isto se justifica em função de maior proporção de frutos de menor tamanho para a Dover, que pode ser estimado a partir da MMC - MMF, conforme abordado. De fato, Duarte Filho et al. (2003) observaram que o problema da Dover é a grande produção de frutos com tamanho e massa abaixo do padrão comercial, devido às características de suas inflorescências, que possuem muitas ramificações. Estes mesmos autores, bem como Oliveira e Scivittaro (2006), também reportaram a superioridade da Camarosa para a produção comercial de frutos.

Das correlações estimadas entre as variáveis avaliadas (Tabela 4), algumas merecem destaque. Entre a variável NEM e as demais, nenhuma foi significativa, mas todas positivas. Já para a variável NMM, embora não significativas, todas foram negativas, exceto com PRC e NFTP. Considerando-se válida a assertiva de que clones oriundos de matrizes com mais mudas também originarão maior número de ramos, não é de surpreender que estes clones também produzirão maior número de frutos. Por outro lado, um excessivo número de ramos leva a um dispêndio maior de energia na parte vegetativa, diminuindo o peso de cada fruto, justificando as estimativas negativas para as demais correlações. A correlação estimada ente NMM e PRC (Tabela 4) também chama a atenção ante a constatação de que matrizes com maior número de mudas tendem a produzir descendentes mais precoces.

Já as correlações entre PRC e as demais variáveis de produção, embora não significativas, são negativas e não desprezíveis (Tabela 4), podendose inferir que a seleção de clones mais precoces, principalmente se for conduzida por vários ciclos, poderá levar a um aumento da expressão das demais. De fato, sendo a mais tardia de todas as cultivares, Toyonoka foi a que apresentou menor desempenho para as demais variáveis (Tabela 3 ).

A estimativa da correlação entre PTP ou PTha é menor com NFTP, do que com NFCP, o que leva a inferir que a produtividade de frutos é determinada em maior grau pela maior massa de um menor número de frutos (a seleção dos frutos comerciais é baseada principalmente no tamanho) do que pelo maior número de frutos. Esta assertiva é reforçada quando se consideram as estimativas das correlações entre PCP ou PCha e NFTP e NFCP, baixíssima para o primeiro caso e próxima de $100 \%$ para o segundo (Tabela 4).

TABELA 1- Temperatura média máxima e média mínima durante o período para a obtenção das mudas e produção de morangos. Datas-MG.

\begin{tabular}{|c|c|c|c|c|c|}
\hline \multirow[b]{2}{*}{ Mês/ano } & \multicolumn{2}{|c|}{ Temperatura } & \multirow[b]{2}{*}{ Mês/ano } & \multicolumn{2}{|c|}{ Temperatura } \\
\hline & $\begin{array}{l}\text { Média } \\
\text { máxima } \\
\left({ }^{\circ} \mathrm{C}\right)\end{array}$ & $\begin{array}{l}\text { Média } \\
\text { mínima } \\
\left({ }^{\circ} \mathrm{C}\right)\end{array}$ & & $\begin{array}{l}\text { Média } \\
\text { máxima } \\
\left({ }^{\circ} \mathrm{C}\right)\end{array}$ & $\begin{array}{l}\text { Média } \\
\text { mínima } \\
\left({ }^{\circ} \mathrm{C}\right)\end{array}$ \\
\hline set/11 & 25,19 & 13,96 & $\mathrm{abr} / 12$ & 19,76 & 18,67 \\
\hline out/11 & 24,66 & 15,30 & $\mathrm{mai} / 12$ & 16,97 & 16,02 \\
\hline nov/11 & 20,33 & 14,59 & jun/12 & 15,49 & 14,22 \\
\hline $\operatorname{dez} / 11$ & 21,58 & 16,77 & jul/12 & 16,63 & 15,42 \\
\hline $\mathrm{jan} / 12$ & 24,55 & 16,22 & ago/12 & 17,33 & 16,23 \\
\hline $\mathrm{fev} / 12$ & 25,83 & 15,80 & set $/ 12$ & 17,37 & 16,08 \\
\hline $\operatorname{mar} / 12$ & 26,87 & 15,63 & out $/ 12$ & 20,06 & 18,76 \\
\hline
\end{tabular}


TABELA 2- Número de estolões por matriz, de mudas por matriz e por hectare, em diferentes cultivares de morangueiro, Datas-MG.

\begin{tabular}{cccc}
\hline Cultivares & $\begin{array}{c}\mathrm{N}^{o} \text { de estolão } \\
\text { matriz }^{-1}\end{array}$ & $\begin{array}{c}\mathrm{N}^{o} \text { de mudas } \\
\text { matriz }^{-1}\end{array}$ & $\begin{array}{c}\mathrm{N}^{\circ} \text { de mudas } \\
\text { ha }^{-1}\end{array}$ \\
\hline Aromas & 8,7 & 83,0 & 332.000 \\
Camarosa & 20,2 & 117,0 & 468.000 \\
Campinas & 16,5 & 112,2 & 449.000 \\
Diamante & 7,0 & 71,0 & 284.000 \\
Dover & 17,5 & 221,7 & 887.000 \\
Festival & 21,5 & 157,5 & 630.000 \\
Oso Grande & 17,2 & 112,0 & 448.000 \\
Toyonoka & 13,7 & 152,5 & 610.000 \\
\hline Média & 15,3 & 128,3 & 513.500 \\
\hline
\end{tabular}

TABELA 3- Estimativas de médias das variáveis: precocidade em dias (PRC); produção total em $\mathrm{g} \mathrm{planta}^{-1}$ (PTP) e em t ha-1 (PTha); produção comercial em g planta-1 (PCP) e em t ha ${ }^{-1}$ (PCha); número de frutos totais e comerciais por planta (NFTP e NFCP), respectivamente; massa média em $\mathrm{g}_{\text {fruto }^{-1}}$ (MMF); e massa média comercial em $\mathrm{g}$ fruto $^{-1}$ (MMC), de oito cultivares de morangueiro, Datas-MG.

\begin{tabular}{cccccccccc}
\hline Cultivares & PRC & PTP & PTha & PCP & PCha & NFTP & NFCP & MMF & MMC \\
\hline Aromas & $66,00 \mathrm{~b}$ & $401,78 \mathrm{a}$ & $44,64 \mathrm{a}$ & $255,00 \mathrm{~b}$ & $28,33 \mathrm{~b}$ & $42,31 \mathrm{~b}$ & $19,08 \mathrm{~b}$ & $9,50 \mathrm{~b}$ & $13,33 \mathrm{~b}$ \\
Camarosa & $72,50 \mathrm{~b}$ & $526,45 \mathrm{a}$ & $58,49 \mathrm{a}$ & $397,25 \mathrm{a}$ & $44,14 \mathrm{a}$ & $43,87 \mathrm{~b}$ & $26,48 \mathrm{a}$ & $12,06 \mathrm{a}$ & $15,06 \mathrm{a}$ \\
Campinas & $75,50 \mathrm{~b}$ & $432,03 \mathrm{a}$ & $48,00 \mathrm{a}$ & $181,40 \mathrm{c}$ & $20,16 \mathrm{c}$ & $58,86 \mathrm{a}$ & $14,66 \mathrm{c}$ & $7,33 \mathrm{c}$ & $12,34 \mathrm{~b}$ \\
Diamante & $65,00 \mathrm{~b}$ & $366,04 \mathrm{a}$ & $39,74 \mathrm{a}$ & $275,79 \mathrm{~b}$ & $30,64 \mathrm{~b}$ & $31,83 \mathrm{c}$ & $19,54 \mathrm{~b}$ & $11,50 \mathrm{a}$ & $14,16 \mathrm{a}$ \\
Dover & $85,00 \mathrm{a}$ & $400,83 \mathrm{a}$ & $43,99 \mathrm{a}$ & $197,91 \mathrm{c}$ & $21,99 \mathrm{c}$ & $57,10 \mathrm{a}$ & $15,47 \mathrm{c}$ & $7,01 \mathrm{c}$ & $12,78 \mathrm{~b}$ \\
Festival & $78,75 \mathrm{a}$ & $468,01 \mathrm{a}$ & $52,00 \mathrm{a}$ & $378,92 \mathrm{~b}$ & $42,10 \mathrm{~b}$ & $38,57 \mathrm{~b}$ & $25,14 \mathrm{a}$ & $12,11 \mathrm{a}$ & $15,07 \mathrm{a}$ \\
Oso Grande & $71,25 \mathrm{~b}$ & $367,76 \mathrm{a}$ & $40,86 \mathrm{a}$ & $295,53 \mathrm{~b}$ & $32,84 \mathrm{~b}$ & $30,69 \mathrm{c}$ & $21,14 \mathrm{~b}$ & $11,92 \mathrm{a}$ & $13,97 \mathrm{a}$ \\
Toyonoka & $89,25 \mathrm{a}$ & $176,00 \mathrm{~b}$ & $19,56 \mathrm{~b}$ & $97,40 \mathrm{~d}$ & $10,82 \mathrm{~d}$ & $21,99 \mathrm{c}$ & $8,05 \mathrm{~d}$ & $8,03 \mathrm{c}$ & $12,09 \mathrm{~b}$ \\
\hline Média & 75,41 & 390,70 & 43,41 & 259,90 & 28,88 & 40,65 & 18,70 & 9,95 & 13,61 \\
\hline CV $(\%)$ & 9,04 & 20,26 & 20,26 & 21,33 & 21,34 & 20,54 & 21,50 & 7,36 & 6,31 \\
\hline
\end{tabular}

Médias seguidas pela mesma letra não diferem entre si, pelo teste de $\operatorname{Scott}-\operatorname{Knott}(\mathrm{p}<0,05)$. 
TABELA 4- Estimativas de correlações entre as variáveis: número de estolões (NEM) e de mudas (NMM) por matriz; precocidade em dias (PRC); produção total em g planta $^{-1}$ (PTP) e em t ha-1 (PTha); produção comercial em g planta $^{-1}(\mathrm{PCP})$ e em tha-1 $(\mathrm{PCha})$; número de frutos totais e comerciais por planta (NFTP e NFCP), respectivamente; massa média em g fruto $^{-1}$ (MMF); e massa média

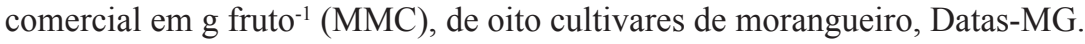

\begin{tabular}{|c|c|c|c|c|c|c|c|c|c|}
\hline \multicolumn{10}{|c|}{ Correlações estimadas } \\
\hline & PRC & РTP & PTha & PCP & PCha & NFTP & NFCP & MMF & MMC \\
\hline NEM & $46,93 \%$ & $44,40 \%$ & $45,84 \%$ & $38,62 \%$ & $38,64 \%$ & $28,96 \%$ & $36,25 \%$ & $13,67 \%$ & $31,54 \%$ \\
\hline NMM & $84,76 \%$ & $-8,44 \%$ & $-8,34 \%$ & $-23,05 \%$ & $-23,05 \%$ & $29,93 \%$ & $-24,90 \%$ & $-45,38 \%$ & $-23,75 \%$ \\
\hline PRC & & $-44,73 \%$ & $-43,95 \%$ & $-51,49 \%$ & $-51,49 \%$ & $0,32 \%$ & $-56,38 \%$ & $-55,17 \%$ & $-47,49 \%$ \\
\hline PTP & & & $99,95 \%$ & $79,72 \%$ & $79,72 \%$ & $61,75 \%$ & $83,39 \%$ & $39,97 \%$ & $66,35 \%$ \\
\hline PTha & & & & $79,72 \%$ & $79,73 \%$ & $61,49 \%$ & $83,35 \%$ & $39,93 \%$ & $66,08 \%$ \\
\hline PCP & & & & & $100,00 \%$ & $3,05 \%$ & $99,46 \%$ & $85,51 \%$ & $97,43 \%$ \\
\hline PCha & & & & & & $3,06 \%$ & $99,46 \%$ & $85,50 \%$ & $97,43 \%$ \\
\hline NFTP & & & & & & & $9,85 \%$ & $-46,09 \%$ & $-15,16 \%$ \\
\hline NFCP & & & & & & & & $82,50 \%$ & $95,14 \%$ \\
\hline $\mathrm{MMF}$ & & & & & & & & & $91,92 \%$ \\
\hline \multicolumn{10}{|c|}{ Nível de significância } \\
\hline & PRC & PTP & PTha & PCP & PCha & NFTP & $\mathrm{NFCP}$ & MMF & $\mathrm{MMC}$ \\
\hline NEM & $24,07 \%$ & $27,05 \%$ & $25,33 \%$ & $34,46 \%$ & $34,44 \%$ & $48,66 \%$ & $37,75 \%$ & $74,69 \%$ & $44,67 \%$ \\
\hline NMM & $0,79 \%$ & $84,26 \%$ & $84,43 \%$ & $58,29 \%$ & $58,29 \%$ & $47,14 \%$ & $55,20 \%$ & $25,87 \%$ & $57,12 \%$ \\
\hline $\mathrm{PRC}$ & & $26,64 \%$ & $27,59 \%$ & $19,17 \%$ & $19,17 \%$ & $99,40 \%$ & $14,56 \%$ & $15,63 \%$ & $23,44 \%$ \\
\hline PTP & & & $0,00 \%$ & $1,78 \%$ & $1,78 \%$ & $10,40 \%$ & $1,01 \%$ & $32,70 \%$ & $7,37 \%$ \\
\hline PTha & & & & $1,78 \%$ & $1,78 \%$ & $10,47 \%$ & $1,01 \%$ & $32,71 \%$ & $7,44 \%$ \\
\hline PCP & & & & & $0,00 \%$ & $94,29 \%$ & $0,00 \%$ & $0,68 \%$ & $0,00 \%$ \\
\hline PCha & & & & & & $94,27 \%$ & $0,00 \%$ & $0,68 \%$ & $0,00 \%$ \\
\hline NFTP & & & & & & & $81,65 \%$ & $25,04 \%$ & $72,01 \%$ \\
\hline $\mathrm{NFCP}$ & & & & & & & & $1,17 \%$ & $0,03 \%$ \\
\hline $\mathrm{MMF}$ & & & & & & & & & $0,12 \%$ \\
\hline
\end{tabular}




\section{CONCLUSÕES}

As cultivares que apresentam superioridade para praticamente todas as variáveis são Camarosa e Festival, o que permite sua recomendação para a região de cultivo estudada.

A cultivar Toyonoka foi a que apresentou menor desempenho para as variáveis analisadas.

As cultivares mais precoces tendem a apresentar aumento na produção de frutos.

\section{AGRADECIMENTOS}

Ao CNPq, FAPEMIG e Capes, pelas bolsas e recursos disponibilizados para o desenvolvimento do projeto; à empresa Multiplanta Biotecnologia Vegetal Ltda., pela doação das matrizes de morangueiro; à empresa Mape Frutas Ltda., pela concessão da área experimental e pelo apoio na condução do projeto.

\section{REFERÊNCIAS}

AGRIANUAL: anuário da agricultura brasileira. Morango. 13.ed. São Paulo: FNP Consultoria e AgroInformativos, 2008. p. 419.

CALVETE, E.O.; MARIANI, F.; WESP, C.L.; NIENOW, A.A.; CASTILHOS, T.; CECCHETTI, D. Fenologia, produção e teor de antocianinas de cultivares de morangueiro. Revista Brasileira de Fruticultura, Jaboticabal, v. 30, n. 2, p. 396-401, 2008. Disponível em: < http://www.scielo.br/pdf/ rbf/v30n2/a22v30n2.pdf $>$. Acesso em: 2 fev.2013.

CAMARGO, L. K. P.; RESENDE, J. T. V. DE; GAlvÃO, A. G.; CAMARGO, C. K.; BAIER, J. E. Desempenho produtivo e massa média de frutos de morangueiro obtidos de diferentes sistemas de cultivo. Ambiência, Guarapuava, v. 6, n. 2, p. 281288, 2010. Disponível em: $<$ http://revistas.unicentro. br/index.php/ambiencia/article/view/547/1034>. Acesso em: 10 jan. 2013.

CRUZ, C. D. Genes - a software package for analysis in experimental statistics and quantitative genetics. Acta Scientiarum Agronomy, Maringá, v. 35, p. 271-276, 2013. Disponível em: $\leq$ http:// periodicos.uem.br/ojs/index.php/ActaSciAgron/ article/view/21251/pdf $>$. Acesso em: 10 ago. 2013.
DUARTE FILHO, J.; ANTUNES, L.E.C.; PÁDUA, J.G. Cultivares. In: DIAS, M.S.C. Morango conquistando novas fronteiras 28. Belo Horizonte: Epamig, 2007. p.20-23. (Informe Agropecuário, 236)

DUARTE FILHO, J.; ANTUNES, L.E.C.; PÁDUA, J.G. Introdução e avaliação de cultivares de morangueiro no sul de Minas Gerais. Horticultura Brasileira, Brasília, v.21, n.2, 2003. Suplemento. CDROM. Disponível em: $<$ http://www.abhorticultura. com.br/biblioteca/arquivos/Download/Biblioteca/ olme4014c.pdf > . Acesso em: 10 dez. 2012.

EMBRAPA. Estudo de caso da eficiência econômica e viabilidade financeira da produção de morango em sistema semi-hidropônico. Bento Gonçalves, 2011. p.1-16. (Circular Técnica, 88). Disponível em: $\leq$ http://www.cnpuv.embrapa.br/publica/circular/ cir088.pdf $>$. Acesso em: 25 mar. 2014.

GUIMARÃES, A. G.; VIEIRA, G.; BATISTA, A. G.; PINTO, N. V. D.; VIANA, D. J. V. Características físico-químicas e antioxidantes de cultivares de morangueiro no Vale do Jequitinhonha. Tecnologia \& Ciência Agropecuária, João Pessoa, v. 7, n. 2, p. 35-40, 2013. Disponível em: <www.emepa.org. br/revista/volumes/tca_v7_n2 jun/tca7206.pdf $>$. Acesso em: 15 jun. $201 \overline{3}$.

OLIVEIRA, C. M.; GONÇALVES, A.; VIEIRA, G.; DESSIMONI, N. A. V. Avaliação físicoquímica e perda de umidade do morango in natura desidratado em diferentes temperaturas, submetidos ou não a pasteurização. Revista Brasileira de Armazenamento, Viçosa, MG, v. 35, p. 107-114, 2010a.

OLIVEIRA, C.S.; COCCO, C.; ANDRIOLO, J.L.; BISOGNIN, D.A.; ERPEN, L.; FRANQUEZ, G.G. Produção e qualidade de propágulos de morangueiro em diferentes concentrações de nitrogênio no cultivo sem solo. Revista Ceres, Viçosa, MG, v. 57, n.4, p. 554-559, 2010b. Disponível em: $<$ http://www.ceres. ufv.br/ceres/revistas/V57N004P17808.pdf $>$. Acesso em: 30 jul. 2013.

OLIVEIRA, R. P.; SCIVITTARO, W. B. Desempenho produtivo de mudas nacionais e importadas de morangueiro. Revista Brasileira de Fruticultura, Jaboticabal, v. 28, n. 3, p. 520-522, 2006. Disponível em: <http://www.scielo.br/pdf/rbf/v28n3/40.pdf>. Acesso em: 10 jan. 2013. 
OLIVEIRA, R. P.; SCIVITTARO, W. B. Produção de frutos de morango em função de diferentes períodos de vernalização das mudas. Horticultura Brasileira, Brasília, v. 27, p. 91-95, 2009. Disponível em: $\leq$ http://www.scielo.br/pdf/hb/v27n1/18.pdf $>$. Acesso em: 22 jan. 2013.

OLIVEIRA, R. P.; SCIVITTARO, W. B. Produção de morangueiro cultivar "Cegnidarem" sob túnel plástico. Ciência Rural, Santa Maria, v. 38, n. 9, p. 2613-2617, 2008. Disponível em: $\leq$ http://www. scielo.br/pdf/cr/v38n9/a33cr302.pdf. $>$. Acesso em: 5 fev. 2013.

OLIVEIRA, R. P.; SCIVITTARO, W. B.; FINKENAUER, D. Produção de morangueiro da cv. camino real em sistema de túnel. Revista Brasileira de Fruticultura, Jaboticabal, v. 30, n. 3, p. 681-684, 2008. Disponível em: <http://www. scielo.br/pdf/rceres/v58n5/v58n5a13.pdf $>$. Acesso em: 1 mar. 2013.

OTTO, R. F.; MORAKAMI, R. K.; REGHIN, M.Y.; CAIRES, E.F. Cultivares de morango de dia neutro: produção em função de doses de nitrogênio durante o verão. Horticultura Brasileira, Brasília, v. 27, n. 2 p. 217-221, 2009. Disponível em: <http://www. scielo.br/pdf/hb/v27n2/v27n2a17.pdf $>$. Acesso em: 5 maio. 2013.

RIOS, S.A.L. Melhoramento genético do morangueiro. In: DIAS, M.S.C. Morango conquistando novas fronteiras 28. Belo Horizonte: Epamig, 2007. p.1419. (Informe Agropecuário, 236)
ROSA, H. T.; STRECK, N. A.: WALTER, L. C.; ANDRIOLO, J. L.; SILVA, M. R. Crescimento vegetativo e produtivo de duas cultivares de morango sob épocas de plantio em ambiente subtropical. Revista Ciência Agronômica, Fortaleza, v. 44, n. 3, p. 604-613, 2013. Disponível em: $\leq$ http://www. scielo.br/pdf/rca/v44n3/a24v44n3.pdf $>$. Acesso em: 11 ago. 2013.

SILVA, A.F.; DIAS, M.S.C.; MARO, L.A.C. Botânica e fisiologia do morangueiro. In: DIAS, M.S.C. Morango conquistando novas fronteiras 28. Belo Horizonte: Epamig, 2007. p.7-13. (Informe Agropecuário, 236)

STRASSBURGER, A. S.; PEIL, R. M. N.; SCHWENGBER, J. E.; MEDEIROS, C. A. B.; MARTINS, D. S.; SILVA, J. B. Crescimento e produtividade de cultivares de morangueiro de "dia neutro" em diferentes densidades de plantio em sistema de cultivo orgânico. Bragantia, Campinas, v. 69, n. 3, p. 623-630, 2010. Disponível em: $\leq$ http://www.scielo.br/scielo.php?pid=S0006-

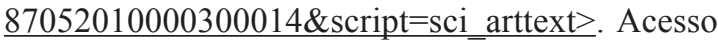
em: 8 jun. 2013.

TESSARIOLI NETO, J.; ORTIGOZA, L. E. R.; VERDIAL, M. F. Produção de mudas de cultivares de morangueiro em duas épocas de coleta. Horticultura Brasileira, Brasília, v.21, n.2, p.231-233, 2003. Disponível em: $\leq$ http://www.scielo.br/pdf/hb/v21n2/ a22v21n2.pdf >. Acesso em: 5 fev. 2013. 